\title{
Kompetensi Guru Pendidikan Jasmani Olahraga Kesehatan di Bojonegoro
}

\section{Competency of Health Sports Physical Education Teachers in Bojonegoro}

\author{
Hasan Saifuddin¹, Benny Widya Priadana², Nurman Ramadhan ${ }^{3}$ \\ 1,2,3 Fakultas Keguruan dan Ilmu Pendidikan, Universitas Nahdlatul Ulama Sunan Giri Bojonegoro \\ email: hasan@unugiri.ac.id ${ }^{1}$, benny.wp@unugiri.ac.id ${ }^{2}$, nurman@unugiri.ac.id ${ }^{3}$ \\ doi : https://doi.org/10.20884/1.paju.2021.3.1.4814
}

\begin{abstract}
Abstrak
Kualitas hasil pembelajaran olahraga sangat di tentukan oleh kompetensi guru PJOK. Untuk pembinaan keprofesian guru diperlukan pengukuran kompetensi guru PJOK secara berkala. Penelitian ini bertujuan mengetahui kompetensi guru PJOK di Bojonegoro. Jenis penelitian yang digunakan yakni desciptive study dengan metode survey kadar keguruan guru PJOK untuk mengetahui kompetensi guru. Subjek penelitian ini adalah Guru PJOK di Sekolah SD, SMP,dan SMA di Bojonegoro berjumlah 30 orang menggunakan teknik accidental sampling. Instrumen penelitian menggunakan kuisioner kadar keguruan PJOK dengan mengunakan rentang nilai 0\%-100\% (Suroto, 2016). Kuesioner ini menggunakan skala empat poin tipe Likert (1 = katergori kurang, 2 = kategori biasa, 3 = kategori baik, 4 = kategori hebat). Hasil penelitian kadar keguruan kompetensi guru PJOK secara keseluruhan hasil dari 30 orang sampel penelitian guru PJOK berdasarkan semua tingkatan yang masuk pada kategori kurang dengan skor persentase 23,3\%, guru PJOK yang masuk kategori biasa dengan skor persentase 30,0\%, guru PJOK yang masuk kategori baik dengan skor persentase 33,3\% dan guru PJOK yang masuk kategori hebat dengan skor persentase $13,3 \%$. Kesimpulan dari hasil penelitian ini adalah masih diperlukan peningkatan kompetensi guru PJOK agar lebih baik dalam konteks proses dan hasil pembelajaran.
\end{abstract}

Kata Kunci : Bojonegoro, Guru PJOK, Kompetensi

\begin{abstract}
The quality of sports learning outcomes is largely determined by the competence of PJOK teachers. For teacher professional development, it is necessary to measure the competence of PJOK teachers on a regular basis. This review plans to decide the ability of PJOK instructors in Bojonegoro. The sort of examination utilized is an unmistakable report with a study technique for PJOK instructors' educator levels to decide instructor ability. The subjects of this review were PJOK instructors in rudimentary, center, and secondary school schools in Alamat Koresponden: Fakultas Keguruan dan IImu Pendidikan, Universitas Nahdlatul Ulama Sunan Giri Bojonegoro

Email: hasan@unugiri.ac.id (c) (i)


Bojonegoro adding up to 30 individuals utilizing unintentional inspecting procedure. The examination instrument utilized a PJOK educator level poll by utilizing a worth scope of 0\%-100\% (Suroto, 2016). This poll utilizes a four-point Likert-type scale ( 1 = helpless classification, 2 = ordinary classification, 3 = great classification, 4 = incredible class). The consequences of the exploration on instructor ability levels of PJOK educators in general are the aftereffects of 30 examples of PJOK educator research dependent on all levels that fall into the less class with a rate score of $23.3 \%$, PJOK instructors who fall into the common classification with a rate score of $30.0 \%$, PJOK instructors who in the great classification with a rate score of $33.3 \%$ and PJOK instructors who enter the extraordinary classification with a rate score of $13.3 \%$. The conclusion from the results of this study is that it is still necessary to increase the competence of PJOK teachers to be better in the context of learning processes and outcomes

Keywords: Bojonegoro, Competence, PJOK Teacher

\section{PENDAHULUAN}

Peranan penting pada pembelajaran pendidikan jasmani terletak guru PJOK. Guru menjadikan siswa memahami dan mengerti akan tugas gerak yang di ajarkan oleh guru. Bukan hanya itu saja tetapi menjadikan siswa mengerti akan perannya dalam pembelajaran olahraga sehingga mendapatkan keuntungan kesehatan bagi dirinya.Guru PJOK bertanggungjawab terhadap tugas yang menentukan masa depan olahraga melalui komponen kompetensi guru yang mempunyai kualitas kompetensinya. Perpusnas (2019) Pendidik merupakan tenaga guru profesional yang bertanggung jawab untuk melaksanakan dan merencanakan proses pembelajaran, melaksanakan pendidikan dan pelatihan, menilai hasil pembelajaran ,serta melaksanakan penelitian dan pengabdian kepada masyarakat.

Guru PJOK profesional harus mempunyai keterampilan dalam implementasi pembelajaran. Tujuan pendidikan dan pembelajaran di sekolah tercapai merupakan salah satunya dipengaruhi oleh kompetensi guru. Depdiknas (2019) menyatakan guru harus mempunyai empat kompetensi pedagogik, kepribadian, kompetensi sosial, dan profesional. Kompetensi guru merupakan mutlak dimiliki guru karena sebagai dasar seorang guru yang profesional layak mendapatkan keprofesiannya (Muna, 2016). Tuntutan Guru PJOK harus memiliki kompetensi profesional yang baik agar tujuan pendidikan nasional bisa tercapai. Dari Data Uji Kompetensi Guru (UKG) Nasional pada tahun 2018 nilai rata-rata yakni 75\%, peningkatan kompetensi di tahun 2019 menjadi $80 \%$ dan di tahun 2020 rata-rata kompetensi profesional dan pedagogik guru SD, SMPdan SMA adalah 
Hasan Saifuddin, Benny Widya Priadana \& Nurman Ramadhan | Kompetensi Guru Pendidikan Jasmani Olahraga Kesehatan (PJOK) di Bojonegoro

$60,75 \%$ dan untuk guru, nilai rata-rata kompetensi profesional dan pedagogik adalah 60,05\% (Kemendikbud, 2020).

Berdasarkan hasil UKG ini masih perlu meningkatkan pengembangan kualitas guru. Karena tenaga pengajar pada mapel PJOK disekolah belum mendapatkan haknya secara penuh. Sekolah sebagai penentu kebijakan tidak melihat latar belakang pendidikan guru PJOK untuk bisa mengajar bahkan non keguruan tidak melihat kualifikasi guru sebagai tenaga pengajar PJOK dalam perekrutan tenaga pengajar (Suroto, 2016). Undang-Undang Republik Indonesia No 3 Tahun 2005 Tentang Sistem Keolahragaan Nasional menyatakan pengembangan dan pembinaan yang dilaksanakan guru olahraga melalui proses pembelajaran dari olahraga pendidikan yang berkualifikasi dan mempunyai sertifikat kompetensi.

Kompetensi guru PJOK masa kerja dalam pengalaman kerja tidak menunjukan semakin ahli dalam keterampilannya. Kinerja SDM berdasarkan 5 indikator pendidikan menunjukkan kinerja Direktorat Jenderal Pendidikan Dasar dan Menengah (dikdasmen) termasuk kategori kurang dengan nilai 77,69\% (Kemendikbud RI, 2016). Dengan data ini menyebutkan bahwa beluam adanya peningkatan dan perubahan kualitas guru mendapatkan sertifikasi dalam proses belajar mengajar.

Masa kerja yang lama guru PJOK mengajar tidak menjamin meningkatnya kompetensi yang guru PJOK miliki (Maksum, 2017). Terjadi krisis identitas PJOK di sekolah dikarenakan kurangnya guru PJOK yang berkualitas dalam melaksanakan proses pembelajaran. Guru PJOK perlu melakukan evaluasi, mengoreksi setiap proses pembelajaran dan merefleksi kualitas kinerja mereka. Kompetensi profesional antara guru yang masa kerjanya 1 tahun dengan 21 tahun tidak ada perbedaan kompetensinya (Demir, 2015). Untuk itu, dalam meningkatkan kompetensi dan kualitas kinerja guru PJOK diperlukan penyegaran mulai dari sumber belajar bagi para guru bahwa mengikuti seminar atau pelatihan (Maksum, 2016). Jaminan kepada stakeholder tidak dapat dicapai dengan maksimal tanpa ada pencapaian standar kompetensi guru (Fitriani, 2013).

Kompetensi guru adalah melaksanakan tugas profesi seorang guru harus menguasai meliputi keterampilan, pengetahuan, dihayati, perilaku yang harus dimiliki dan (Depdiknas, 2019). Kompetensi pedagogik merupakan keterampilan atau kemampuan guru memanajemen pembelajaran siswa. Kompetensi profesional adalah menguasai materi pelajaran yang luas harus di miliki guru. Kompetensi kepribadian merujuk pada 
sikap keterampilan dalam berakhlak mulia, berwibawa, teladan siswa, arif, kepribadian yang mantap. Kompetensi Sosial adalah keterampilan guru dalam berinteraksi dengan berkomunikasi secara baik dan efesien baik bersama siswa, guru, orangtua/wali ,dan masyarakat sekitar (Maksum, 2016). Memaksimalkan kemampuan belajar sesuai tujuan pendidikan guru diwajibkan mengembangkan dan mengasah kemampuan kompetensi pedagogik (Supriyandi, 2013). Agar pelaksanaan pembelajaran penjas lebih baik lagi maka Guru PJOK harus mempertahankan dan lebih meningkatkan mutunya (Setiyadi, 2009). Penentu dari hasil pembelajaran dan kualitas proses pembelajaran yakni kompetensi guru. Pemerintah telah membuat skala penilaian Uji Kompetensi Guru (UKG) namun hanya mengukur kompetensi pedagogik dan profesional saja (Suroto, 2016). Dari uji kompetensi terdapat perbedaan skor rata-rata lebih tinggi kompetensi pedagogik dan profesional guru PJOK SMP Negeri dari guru PJOK SMP Swasta (Winarni \& Lismadiana, 2020). Masuk kategori tinggi kompetensi yang di miliki terhadap persepsi guru PJOK (Kurdi \& Putra, 2018)

Untuk itu, diperlukan pengukuran kadar keguruan guna mengetahui dan mengontrol kualitas guru PJOK di Bojonegoro agar dalam mengembangkan dan membina olahraga melalui proses pembelajaran olahraga yang baik. Pengembangan dan pembinaan guru diharapkan mempunyai manfaat dan meningkatkan mutu pendidikan dan kinerja guru adalah pilar utama didunia pendidikan karena itu guru dituntut mengembangkan teknologinya sebagai peningkatan kompetensinya (Dhuhary, 2012).

\section{METODE}

Jenis penelitian yang digunakan yakni desciptive study dengan metode survey kadar keguruan PJOK dengan mengetahui kompetensi guru PJOK di Bojonegoro. Subjek penelitian ini adalah Guru PJOK di Sekolah SD, SMP, SMA di Bojonegoro berjumlah 30 orang menggunakan teknik accidental sampling. Pada pengambilan sampel dilaksanakan pada kegiatan forum guru PJOK di Bojonegoro. Sampel di ambil berdasarkan orang yang ditemui dan hadir di forum guru PJOK. Instrumen penelitian ini menggunakan kuisioner kadar keguruan PJOK dengan mengunakan rentang nilai 0\%-100\% (Suroto, 2016). Kuesioner ini menggunakan skala empat poin tipe Likert $(1=$ katergori kurang, 2 = kategori biasa, 3 = kategori baik, 4 = kategori hebat). 
Hasan Saifuddin, Benny Widya Priadana \& Nurman Ramadhan | Kompetensi Guru Pendidikan Jasmani Olahraga Kesehatan (PJOK) di Bojonegoro

Tabel 1. Kadar Keguruan PJOK

\begin{tabular}{ccc}
\hline Skala Skor & Rentang & Kategori \\
\hline 1 & $0,0 \%-<25,0 \%$ & Kurang \\
\hline 2 & $25,0 \%<50,0 \%$ & Biasa \\
\hline 3 & $50,0 \%<75,0 \%$ & Baik \\
\hline 4 & $75 \%<100,0 \%$ & Hebat
\end{tabular}

Analisis data menggunakan statistik deskriptif. Statistik menggunakan data dalam menganalisis melalui menggambarkan dan mendesripsikandata yang dikumpulkan sebagaimana adanya tanpa menyimpulkan yang berlaku untuk umum (Sugiyono, 2019).

\section{HASIL}

Hasil Penelitian dari pengukuran kadar keguruan bagi guru PJOK di Bojonegoro. Berdasarkan hasil kuisioner data yang di ukur melalui kadar keguruan guru PJOK di Bojonegoro bisa dilihat dalam tabel 2 Hasil Kadar Keguruan Guru PJOK Di Bojonegoro sebagai berikut :

Tabel 2. Hasil Kadar Keguruan Guru PJOK Di Bojonegoro

\begin{tabular}{lccccc}
\hline Kategori & SD & SMP & SMA & Jumlah & Presentase $\%$ \\
\hline Kurang & 2 & 4 & 1 & 7 & $23,3 \%$ \\
\hline Biasa & 2 & 2 & 5 & 9 & $30,0 \%$ \\
\hline Baik & 1 & 4 & 5 & 10 & $33,3 \%$ \\
\hline Hebat & 1 & 1 & 2 & 4 & $13,3 \%$ \\
\hline Total & 6 & 11 & 13 & 30 & $100 \%$ \\
\hline
\end{tabular}

Pada tabel 2 pengukuran kadar keguruan berdasarkan tingkat Sekolah Dasar (SD) atau sederajat guru PJOK yang masuk pada ketegori kurang terdapat 2 orang, kategori biasa terdapat 2 orang, kategori baik terdapat 1 orang dan kategori hebat terdapat 1 orang dari jumlah 6 orang guru PJOK.

Pada pengukuran kadar keguruan berdasarkan tingkat Sekolah Menengah Pertama (SMP) atau sederajat guru PJOK yang masuk pada kategori kurang terdapat 4 orang, kategori biasa terdapat 2 orang, kategori baik terdapat 4 orang dan kategori hebat terdapat 1 orang dari jumlah 11 orang guru PJOK. Dan sedangkan pengukuran kadar keguruan berdasarkan tingkat Sekolah Menegah Atas (SMA) atau sederajat guru PJOK 
yang masuk pada ketegori kurang dengan jumlah 1 orang, kategori biasa terdapat 5 orang, kategori baik terdapat 5 orang dan kategori hebat terdapat 2 orang dari jumlah 13 orang guru PJOK. Berikut ini gambar 1 Hasil Pengukuran Kadar Keguruan Guru PJOK Di Bojonegoro sebagai berikut:

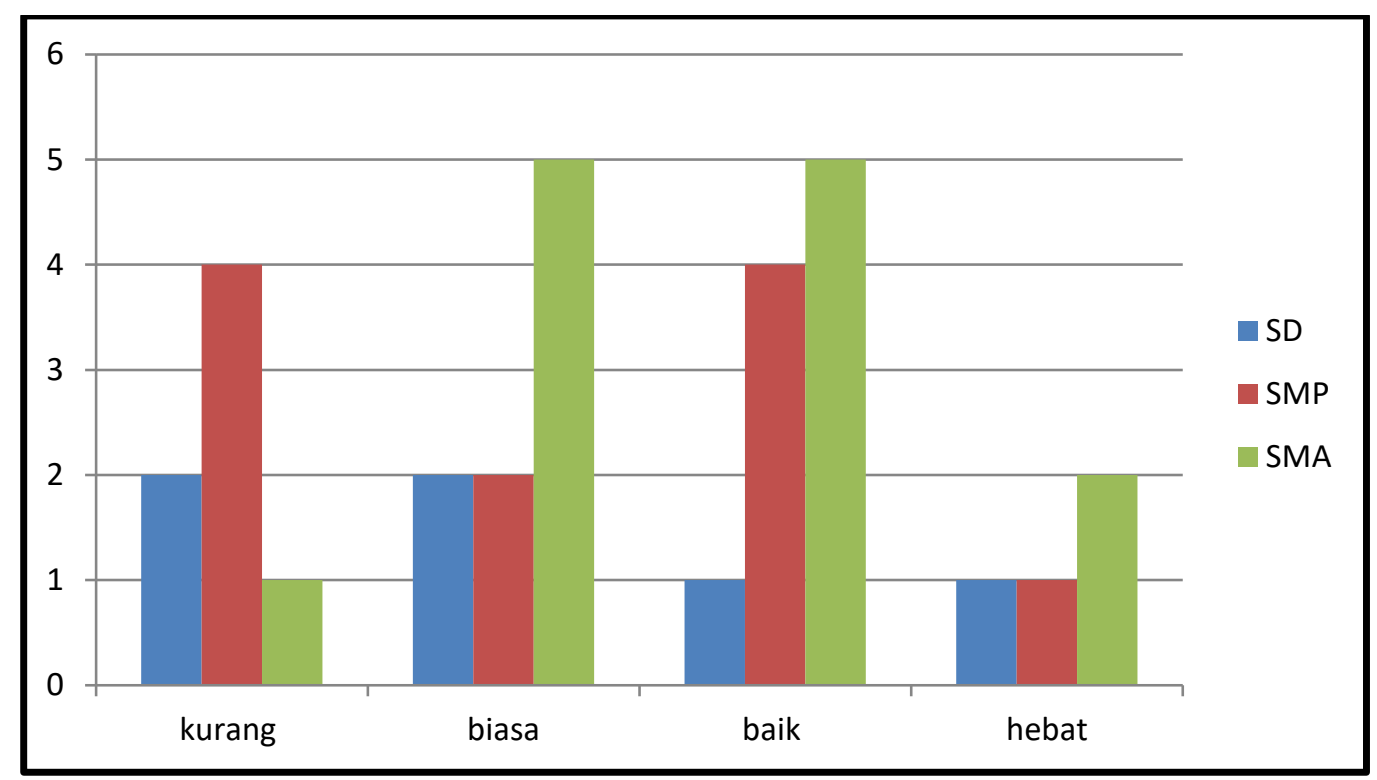

Gambar 1. Hasil Pengukuran Kadar Keguruan Guru PJOK Di Bojonegoro

\section{PEMBAHASAN}

Berdasarkan hasil temuan pada tabel 2 hasil analisis data pengukuran kadar keguruan guru PJOK secara keseluruhan dari semua tingkat lembaga pendidikan Guru PJOK mulai dari SD, SMP, dan SMA bahwa kompetensi guru per dimensi (kompetensi pedagogik, profesional, kompetensi sosial, dan kepribadian). Dari gambar 2 hasil penelitian kadar keguruan kompetensi guru PJOK secara keseluruhan hasil dari 30 orang sampel penelitian guru PJOK berdasarkan semua tingkatan yang masuk pada kategori kurang dengan skor persentase 23,3\%, guru PJOK yang masuk kategori biasa dengan skor persentase 30,0 \%, guru PJOK yang masuk kategori baik dengan skor persentase $33,3 \%$ dan guru PJOK yang masuk kategori hebat dengan skor persentase $13,3 \%$.

Berdasarkan pada hasil penelitian gambar 2 di bawah ini bahwa rata-rata guru PJOK mempunyai kompetensi masuk kategori baik dan biasa bahkan kurang. Data penelitian ini menunjukkan kompetensi guru, di jenjang pendidikan dasar, menengah maupun atas masih memprihatikan. Semua yang sudah mengajar pasti memiliki 
Hasan Saifuddin, Benny Widya Priadana \& Nurman Ramadhan | Kompetensi Guru Pendidikan Jasmani Olahraga Kesehatan (PJOK) di Bojonegoro

kompetensi sebagai guru. Kondisi seperti ini berbanding terbalik pada kenyataan di lapangan. Hal ini di mungkinkan banyak faktor yang mempengaruhi dari hasil pengukuran kadar keguruan guru PJOK. Dengan demikian kompetensi yang dimiliki guru PJOK di Bojonegoro belum merata.

Kompetensi profesional guru penting bagi keprofesiannya dalam pencapaian tujuan pendidikan nasional (Roesdiyanto, 2017). Hal ini penting untuk di tindaklanjuti karena guru perlu pengembangan potensi dalam diri dan memahami apa yang harus dipelajari guru agar mengerti kebutuhan untuk mendukung keterampilan siswa dalam tugas gerak atau perkembangan anak. Disisi lain guru PJOK diharapkan mempunyai kompetensi kepribadian yang baik terutama bersikap kepada siswa karena guru sebagai seorang teladan untuk siswa (Khair, 2018). Menurut Sum, Wallhead, Ha, \& Sit (2018) juga menyampaikan bahwa kesadaran guru dalam meningkatkan kompetensi profesionalnya secara berkelanjutan akan bermanfaat memotivasi siswa dalam berpartisipasi dalam olahraga. Guru dapat menjalankan tugas secara efektif karena adanya kompetensi yang dimiliki. Pekerjaan dan kompetensi saling berhubungan erat, karena dalam konteks ini kompetensi menjadi prasyarat terentu yang harus dipenuhi sebelum melakukan pekerjaannya (Andina, 2018).

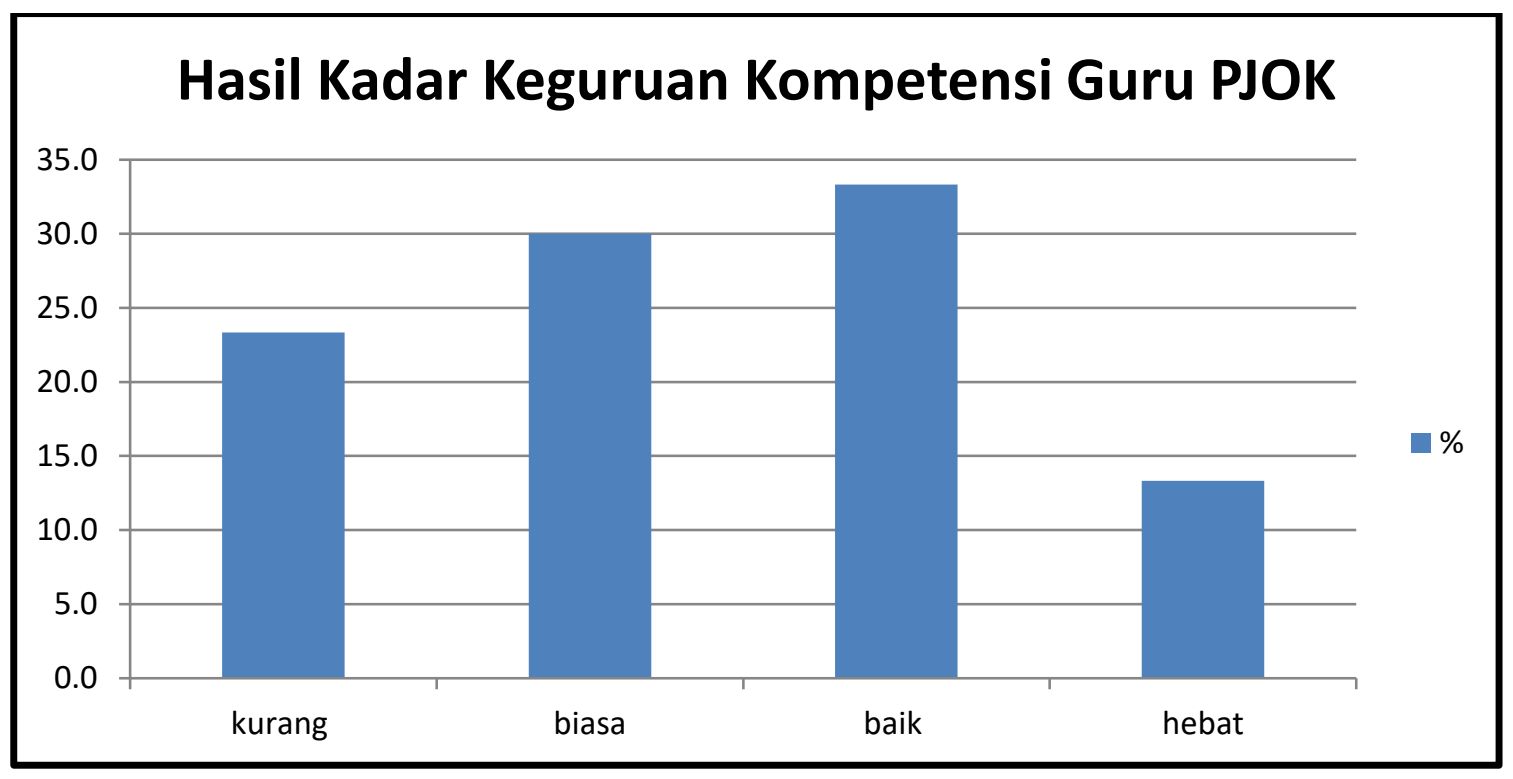

Gambar 2. Hasil Kadar Keguruan Kompetensi Guru PJOK

Kompetensi yang diperlukan guru PJOK, maka sesuai Peraturan Menteri Pendidikan Republik Indonesia Nomor 16 Tahun 2007 Tentang Standar Kualifikasi Akademik dan Kompetensi Guru menyatakan secara nasional kewajiban guru memenuhi standar kompetensi dan kualifikasi akademik. Kompetensi guru harus memenuhi 
komponen kompetensi kepribadian, sosial, pedagogik dan profesional. Kualifikasi akademik adalah keterampilan yang didapatkan dari segi pendidikan yang ditempuh di lembaga pendidikan sesuai bidang yang sesuai profesinya.

Pembimbingan dan pendampingan terhadap guru dapat mengopimalkan keterampilan guru dalam menyusun laporan kinerjanya secara langsung dan intensif (Fitria, Kristiawan, \& Rahmat, 2019). Untuk mengoptimalkan kompetensi guru PJOK maka harus ada penelitian lanjutan agar bisa meningkatkan kompetensi guru dengan pemberian edukasi, pendampingan dengan melakukan kolaborasi, diskusi dengan rekan sejawat sesama profesi guru PJOK saat melakukan pembelajaran rekan sejawat bisa memberikan masukan saran. Pembinaan profesional guru dilakukan melalui 1)Intensive Development diperoleh melalui pelatihan,bimbingan atau sosialisasi kompetensi melalui KKG, MGMP, 2) Cooperative Development diperoleh melalui kunjungan kerja, sharing pengalaman dengan teman se profesi, 3) Self Directed Development diperoleh melalui kreativitas media ajar, mengikui seminar, aktif dalam mencari bahan ajar (Rahayu, Nugroho, \& Berliani, 2019). Pentingnya dukungan dalam pengajaran yang berkelanjutan bagi guru untuk mencapai perkembangan profesional, hal ini memberikan kepercayaan diri, pengetahuan dan motivasi guru secara umum dalam pembelajaran physical literacy siswa jangka panjang (Wright et al., 2020).

Ketika pemberian edukasi yang menjadi perhatian harus di tekankan adalah guru harus melaksanakan dan memahami kompetensi harus dikembangkan dari kompetensi pedagogik, kepribadian, kompetensi profesional, dan sosial. Menurut Prasetyo \& Priambodo (2020) Kompetensi guru mampu menjadi teladan aktif kreatif dan berintegritas tinggi serta mempunyai kontribusi peningkatan prestasi belajar. Daftar kompetensi guru harus diperbarui secara berkala dan di kembangkan dalam upaya perbaikan kualitas pendidikan dan juga dengan melihat tantangan yang di hadapi kebijakan pendidikan global yang berdampak pada guru (Andina, 2018). Setiap tahun secara bertahap pemerintah melakukan uji kompetensi guru dalam upaya standar mutu guru yang profesional, untuk memantau kinerja guru dan dari segi kompetensi(Prasetyo \& Priambodo, 2020). Continuing Professional Development (PE-CPD) Programme on Phsical Education memberikan kesadaran bagaimana menjadi guru olahraga yang profesional sehingga guru memahami kekurangan dalam segi pengetahuan atau keterampilan (Kim, Sum, Morgan, Man, \& Ma, 2020). 
Hasan Saifuddin, Benny Widya Priadana \& Nurman Ramadhan | Kompetensi Guru Pendidikan Jasmani Olahraga Kesehatan (PJOK) di Bojonegoro

Berdasarkan pembahasan di atas maka pentingnya penguasaan kompetensi dan penerapan dari keterampilan dan pengetahuan seorang guru PJOK karena memberikan kualitas kinerja guru dalam melakukan kegiatan belajar mengajar untuk meningkatkan pengalaman gerak dan terliterasi fisik siswa dengan baik dan dalam manajemen kelas. Kompetensi guru penjas berada di garis depan dalam menarik siswa yang kurang menyukai olahraga (Demir, 2015).

\section{SIMPULAN}

Berdasarkan hasil penelitian kompetensi guru PJOK di Bojonegoro mayoritas berada pada kompetensi masuk kategori baik dengan skor 33,3\% dan biasa dengan skor $30,0 \%$ bahkan kurang dengan skor 23,3\%. Secara keseluruhan bahwa guru PJOK mengerti pengembangan keterampilan diri sebagai guru yang profesional. Dari pembahasan disarankan sekolah memberikan pelatihan kepada guru secara berkala dan berkelanjutan dengan upaya peningkatan kompetensi guru mulai dari kompetensi pedagogik, kepribadian, profesional, dan sosial.

Saran ini diberikan agar guru bisa mengembangkan dan mampu menjalakan tugas keprofesionalannya dengan baik. Terlaksananya pemberian edukasi kepada guru PJOK diharapkan bisa lebih baik lagi dalam menjalankan tugasnya. Evaluasi kinerja guru penting dilaksanakan oleh pihak sekolah yakni kepala sekolah atau waka sekolah agar bisa mendeteksi kekurangan dan kelebihan guru terkait kompetensinya. Dengan hal tersebut maka guru PJOK bisa terbantu dalam mengevaluasi dirinyadan peningkatan keterampilan dirinya sebagai guru PJOK yang kompeten di bidangnya. Evaluasi bisa dilaksanakan 1-3 bulan sekali dilakukan oleh rekan kerja, pimpinan sekolah.

\section{REFERENSI}

Andina, E. (2018). Efektivitas Pengukuran Kompetensi Guru. Aspirasi: Jurnal Masalahmasalah Sosial, 9(2), 204-220. https://doi.org/10.46807/aspirasi.v9i2.1103

Demir, E. (2015). Assessment Of Professional Personality Competence Of Physical Education Teachers Working In Canakkale. Pamukkale Journal of Sport Sciences, 6(2), 17-32.

Depdiknas. (2019). Undang-Undang Republik Indonesia Nomor 14 Tahun 2005 Tentang Guru dan Dosen. Jakarta. Diambil dari http://luk.staff.ugm.ac.id/atur/UU142005GuruDosen.pdf 
Dhuhary, A. A. (2012). Peningkatan Kompetensi Guru Pendidikan Jasmani, Olahraga dan Kesehatan. Prosiding Seminar Nasional Profesional Tenaga Profesi PJOK, (1), 294-306.

Fitria, H., Kristiawan, M., \& Rahmat, N. (2019). Upaya Meningkatkan Kompetensi Guru Melalui Pelatihan Penelitian Tindakan Kelas. Abdimas Unwahas, 4(1), 14-25. https://doi.org/10.31942/abd.v4i1.2690

Fitriani, N. A. (2013). Kompetensi Guru PJOK Yang Bersertifikat Pendidik SMP Yogyakarta.

Indonesia, P. R. Undang-Undang Republik Indonesia No.3 Tahun 2005 Tentang Sistem Keolahragaan Nasional. , (2005). Jakarta.

Kemendikbud. (2020). Data Neraca Pendidikan Daerah. Diambil dari Kemendikbud website: https://npd.kemdikbud.go.id/?appid=ukg.

Kemendikbud RI. (2016). Sumber Daya Manusia Pendidikan Dasar dan Menengah. In Bastari \& S. Sofiah (Ed.), Bidang Pendayagunaan dan Pelayanan Data dan Kebudayaan, Statistik Pendidikan dan Kebudayaan, Kementerian Pendidikan dan Kebudayaan. Jakarta: Pusat Data Dan Statistik Pendidikan Dan Kebudayaan. Diambil dari http://publikasi.data.kemdikbud.go.id/uploadDir/isi_C3E61ED4-94A4-4C8EAFEE-091C89F6BF53_.pdf

Khair, A. (2018). Kompetensi Guru PJOK DI SD Negeri Sejangkung.

Kim, R., Sum, W., Morgan, K., Man, M., \& Ma, S. (2020). The Influence of a Customized Continuing Professional Development Programme on Physical Education Teachers ' Perceived Physical Literacy and Efficacy Beliefs. Prospects, (0123456789). https://doi.org/10.1007/s11125-020-09471-4

Kurdi, \& Putra, M. F. P. (2018). Kompetensi Guru PJOK : Antara Harapan dan Kenyataan. Prosiding Seminar Hasil Penelitian Edisi IV 2018, 2(2004).

Maksum, A. (2016). Paradoks guru pendidikan jasmani. Diambil dari https://www.researchgate.net/publication/303912194

Maksum, A. (2017). Guru Bermutu, Pendidikan Maju. (December 2015). https://doi.org/10.13140/RG.2.2.28902.83527

Muna, M. K. (2016). Kompetensi Profesional Guru Pendidikan Jasmani Olahraga Dan Kesehatan. Prosiding Seminar Nasional Profesional Tenaga Profesi PJOK, 209220.

Nasional, M. P. (2007). Peraturan Menteri Pendidikan Nasional Nomor 16 Tahun 2007 Tanggal 4 Mei 2007 Standar Kualifikasi Akademik Dan Kompetensi Guru. 
Hasan Saifuddin, Benny Widya Priadana \& Nurman Ramadhan | Kompetensi Guru Pendidikan Jasmani

Perpusnas, P. (2019). Undang-Undang Republik Indonesia Nomor 20 Tahun 2003 Tentang Sistem Pendidikan Nasional. Jakarta. Diambil dari https://pusdiklat.perpusnas.go.id/

Prasetyo, W. D., \& Priambodo, A. (2020). Studi Evaluatif Tingkat Kompetensi Guru Pendidikan Jasmani Olahraga Dan Kesehatan. 6(1), 15-26.

Rahayu, N. P., Nugroho, J. P., \& Berliani, T. (2019). Pembinaan Profesional Guru SD Daerah Terpencil. Equity in Education Journal, 1(1), 62-72.

Roesdiyanto. (2017). Kompetensi Profesional Guru Pendidikan Jasmani, Olahraga Dan Kesehatan (Dalam Kompetensi Inti Pemahaman Tujuan Pembelajaran Dan Memilih Materi Pembelajaran Sesuai Dengan Tingkat Perkembangan Siswa. Prosiding Seminar Nasional Profesionalisme Tenaga Profesi Pjok, hal. 610-616.

Setiyadi, W. (2009). SUrvei Persepsi Guru Non Pendidikan Jasmani Guru Pendidikan Jasmani Olahraga Dan Kesehatan Tingkat Smp Se Kecamatan Musuk. Universitas Negeri Semarang.

Sugiyono. (2019). Metode Penelitian Kuantitatif Kualitatif dan R\&D (Edisi Kedu; M. Dr. Ir Sutopo, S.Pd., Ed.). Bandung: ALFABETA CV. Diambil dari www.cvalfabeta.com

Sum, K. W. R., Wallhead, T., Ha, S. C. A., \& Sit, H. P. C. (2018). Effects of Physical Education Continuing Professional Development on Teachers 'Physical Literacy and Self-efficacy and Students ' Learning Outcomes. International Journal of Educational Research, $\quad$ 88(January), $1-8$. https://doi.org/10.1016/j.jer.2018.01.001

Supriyandi. (2013). Survei Kompetensi Pedagogik Guru Pendidikan Jasmani Sekolah Menengah Pertama Yang Telah Mendapatkan Sertifikasi Ketapang.

Suroto. (2016). Seminar Nasional Tema Invasi Dan Hilirisasi Hasil Penelitian Untuk Kesejaheraan Masyarakat (I. wayan Susila, Suroto, \& Tukiran, Ed.). Surabaya: Fakultas MIPA Universitas Negeri Surabaya. Diunduh dari fakultasmipa.unesa@gmail.com

Winarni, S., \& Lismadiana. (2020). Physical Education Teacher Competencies Base On Age and Type of School. Jurnal Pendidikan Jasmani Indonesia, 16(1), 101-114. Diambil dari https://journal.uny.ac.id/index.php/jpji

Wright, C., Buxcey, J., Gibbons, S., Cairney, J., Barrette, M., \& Naylor, P. J. (2020). A pragmatic feasibility trial examining the effect of job embedded professional development on teachers' capacity to provide physical literacy enriched physical education in elementary schools. International Journal of Environmental Research and Public Health, 17(12), 1-20. https://doi.org/10.3390/ijerph17124386 